\title{
Histamina e rastreamento de pescado: revisão de literatura
}

\section{Histamine and traceability of fish: literature review}

\section{André Luiz Medeiros de Souza ${ }^{1 *}$, Flávia Aline Andrade Calixto², Eliana de Fátima Marques de Mesquita', Mariana da Purificação Packness², Denise Perdomo Azeredo ${ }^{3}$}

\begin{abstract}
RESUMO: A preocupação com a qualidade do pescado sempre foi um tema recorrente, visto que é um alimento de alto valor nutricional para toda população, porém com grande susceptibilidade à deterioração e formação de substâncias prejudiciais ao homem, caso não sejam obedecidas as condiçôes de conservação. Um exemplo de substância formada é a histamina, uma diamina biogênica primária e heterocíclica, não volátil, termoestável, originada pela descarboxilação da L-histidina, quando as condiçôes de manuseio e estocagem são inadequadas, favorecendo a multiplicação da microbiota natural do pescado. A histamina possui potencial alergênico, podendo causar um quadro de intoxicação no ser humano e, em casos graves, levar à morte. Para tal problema, um sistema de rastreabilidade poderia ser a solução. Seu objetivo é garantir ao consumidor um produto seguro e saudável por meio do controle de todas as fases da produção, industrialização, distribuição e comercialização, possibilitando uma perfeita correlação entre o produto final e a matéria-prima que lhe deu origem. Em diversos países existem atualmente sistemas de rastreabilidade controlando a cadeia de pescado. No Brasil, vários entraves podem ser apontados para a não obrigatoriedade da rastreabilidade em pescado. A divisão de regulamentação do setor entre diferentes órgãos, tais como Ministério da Pesca e Aquicultura (MPA), Ministério da Agricultura, Pecuária e Abastecimento (MAPA) e a Agência Nacional de Vigilância Sanitária (ANVISA), a falta de articulação entre esses órgãos fiscalizadores, a baixa capacitação de mão de obra e a desvalorização dos produtos da pesca, o que trazem a descapitalização da base da cadeia produtiva. De tal maneira, pode-se afirmar que há uma série de desafios para que ocorra a implantação de um sistema de rastreabilidade em território nacional. De acordo com o exposto, este estudo objetivou, através de uma revisão bibliográfica sistemática da literatura, informar a situação atual da escombrotoxicose e da rastreabilidade da histamina em pescado.
\end{abstract}

PALAVRAS-CHAVE: rastreabilidade; histamina; pescado.

\begin{abstract}
Concern about the quality of the fish has always been a recurring theme since it is a food of high nutritional value for the whole population, but with greater ease of formation and decay of harmful substances to man, if not well maintained. An example of a substance formed is histamine, a biogenic diamine primary and heterocyclic, non-volatile, thermoestable, originated by the decarboxylation of L-histidine when the conditions of handling and storage are inadequate, favoring the multiplication of natural microbiota. It has allergen potential and can cause intoxication in humans and, in severe cases, lead to death. For this problem, a traceability system could be the solution. The aim is to ensure the consumer a safe and wholesome product by controlling all stages of production, processing, distribution and marketing, enabling a perfect correlation between the final product and the raw material. In several countries, there are currently traceability systems controlling the chain of fish. In Brazil, several factors can be identified as barriers to the adoption of traceability: different regulatory agencies such as the Ministry of Fisheries and Aquaculture (MPA), Ministry of Agriculture, Livestock and Supply (MAPA), and the National Health Surveillance Agency (ANVISA), the lack of coordination between these sectors, the lack of training of skilled labor and the devaluation of fishery products, which brings decapitalization of the base of the production chain. According to this, there are a number of challenges to deploy a traceability system in the country. This study aimed, through a systematic literature review of the literature, to report the current status of escombrotoxicose and traceability of histamine in fish.
\end{abstract}

KEYWORDS: traceability; histamine; fish. 


\section{INTRODUÇÃO}

O pescado é considerado um alimento de alta digestibilidade, no entanto, pela sua própria composição, é um dos mais perecíveis, necessitando de cuidados adequados de manipulação, desde a captura até o consumo ou industrialização.

$\mathrm{Na}$ literatura há diversos métodos apontados para detectar $o$ acesso aos riscos em pescado, principalmente no que se refere aos utilizados crus pelo consumidor. Nesse caso em particular, há registros de insegurança alimentar, já que a possibilidade de contaminação ou recontaminação é grande, além de crescimento de patógenos e a não utilização das Boas Práticas de Fabricaçáo (BPF), e de alto risco.

A preocupação com a qualidade do pescado sempre foi um tema recorrente, visto tratar-se de um alimento de alto valor nutricional, porém com grande facilidade de deterioração e levando perigo ao homem.

Um produto decorrente da deterioraçáo do pescado é a histamina. Trata-se de uma diamina biogênica primária e heterocíclica, não volátil, termoestável. A histamina é formada na fase de post-mortem do pescado através da descarboxilaçấo bacteriana do aminoácido L-histidina, um aminoácido livre facilmente convertido em histamina pela enzima histidina-descarboxilase quando as condiçôes de manuseio e estocagem são inadequadas, favorecendo a multiplicação de micro-organismos que favoreçam sua atividade (CARMo et al., 2010). A presença de uma microbiota descarboxilase positiva, presente normalmente no peixe vivo, facilitaria a açáo da enzima. A histamina possui potencial alergênico, podendo intoxicar o ser humano e, em casos graves, levar à morte. Alguns surtos vêm sendo registrados. Nos EUA, em 1979-1980, mais de 200 pessoas ficaram doentes depois de consumir dourado importado congelado. Outros incidentes relacionados a anchovas enlatadas e cavala fresca e congelada, pescado azul e vôngoles também foram reportados.

Portanto, faz-se necessário utilizar um mecanismo de defesa para tornar o produto inócuo. Um sistema de rastreamento tem como objetivo garantir ao consumidor um produto seguro e saudável por meio do controle de todas as fases da produção, industrialização, distribuição e comercialização, possibilitando uma perfeita correlaçáo entre o produto final e a matéria-prima que lhe deu origem (Machado; NANTES, 2004).

Com a implementação de um sistema de rastreamento na cadeia produtiva de pescado, casos de intoxicação histamínica poderiam ser controlados, monitorados, evitados e melhor avaliados, reduzindo perigos à saúde do consumidor.

Objetivou-se, através de uma revisão bibliográfica sistemática da literatura, levantar a situação atual do rastreamento da histamina em pescado, sendo essa uma importante etiologia de processos alérgicos.

\section{A FORMAÇÃO DE HISTAMINA EM PESCADO}

A histamina é uma amina não volátil que se origina da descarboxilação do aminoácido histidina, através da enzima histidina-descarboxilase. Parte da histamina provém da autólise microbiana, principalmente da família das enterobactérias (Rodrigues, 2007).

As linhagens bacterianas que geralmente são associadas com o desenvolvimento da histamina estão comumente presentes no ambiente aquático (FDA, 2011; Kim et al., 2001). Essas bactérias pertencem à microbiota natural das brânquias, pele, intestino e da cavidade abdominal do peixe vivo de água salgada, onde não causam quaisquer danos. Kim et al. (2001) afirmaram que Morganella morganii é a mais prevalente e produtiva bactéria formadora de histamina, seguida pelo Proteus vulgaris. Outras de importância na formação da histamina são Hafnia alvei, Escherichia coli e Salmonella spp. (Oliveira et al., 2004).

O início da produção de histamina é decorrente do binômio tempo-temperatura do pescado, formada a partir de temperaturas superiores a $4,4^{\circ} \mathrm{C}$ (Rodrigues, 2007). A manipulaçáo do pescado fora das condiçôes ideais de refrigeração permite que bactérias contaminantes consigam se multiplicar e promover a formação da histamina, pois em seu crescimento algumas delas produzem a enzima histidina-descarboxilase (TAYLOR, 1986).

Arnold; Brown (1978) descreveram que não há produção de histamina em atum mantido a $1^{\circ} \mathrm{C}$ por 42 dias, indicando que a adequada refrigeraçáo pode impedir a formação de histamina. Segundo Gilbert et al. (1980), peixes estocados a $0^{\circ} \mathrm{C}$ com gelo em fusáo permanecem comestíveis por 12 dias com uma concentração final de histamina entre 3 e $4 \mathrm{mg} / 100 \mathrm{~g}$, entretanto, sob temperatura de 12 a $20^{\circ} \mathrm{C}$, rapidamente são obtidas altas concentraçóes.

Em algumas espécies de pescado há uma maior susceptibilidade na formação de histamina, o que ocorre pela maior concentração de histidina livre nelas existente (Huss, 1997). De acordo com a Portaria no 185 do Ministério da Agricultura, Pecuária e Abastecimento (MAPA) (BRASIL, 1997a), entende-se por espécies formadores de histamina as pertencentes às famílias Scombridae, Scombresocidae, Clupeidae, Engraulidae, Coryphaenidae e Pomatomidae. Essas espécies podem vir a formar um nível maior do que $100 \mathrm{ppm}$ de histamina na musculatura, sendo que o nível mínimo para causar sintomas de intoxicação é de 100 ppm (JAY, 2005).

O perigo da histamina em pescado é intensificado pela sua característica de náo volatilidade. Ela pode conferir toxicidade ao produto mesmo antes deste ser considerado deteriorado ou sensorialmente inaceitável (BALDINI, 1982). A intoxicaçấo histamínica é particularmente difícil de ser controlada, uma vez que resiste ao tratamento térmico, podendo estar presente mesmo no produto comercialmente estéril (Veciana-NoguÉs et al., 1997). Segundo Ienistea (1973), a histamina é apenas 
parcialmente destruída após 3 horas de aquecimento a $102^{\circ} \mathrm{C}$ ou 90 minutos a $116^{\circ} \mathrm{C}$ em conservas de sardinha de $250 \mathrm{~g}$. Ou seja, uma vez formada, a histamina pode estar presente no pescado cru, cozido, congelado e até mesmo em conservas, sendo assim de grande perigo ao ser humano.

Vários estudos vêm sendo conduzidos com o objetivo de avaliar o teor de histaminas em pescado. Os resultados encontrados no produto brasileiro encontram-se de acordo com o preconizado pelas legislaçóes brasileira e europeia (Tabela 1). Cabe, no entanto, acrescentar que a amostragem é pontual e não representa a qualidade de todo o lote produzido. No cenário internacional, destaca-se o estudo realizado por TsAi $e t$ al. (2005), que analisaram 33 amostras de cavala salgada (Scomber australasicus) adquiridas nas regióes nordeste e sudeste da Ilha Formosa no período de janeiro a março de 2003, sendo que 2 $(6,1 \%)$ apresentaram teores elevados $(70,1$ e $120,2 \mathrm{mg} / \mathrm{kg}$ de histamina). Esses valores estão acima dos limites preconizados pelas legislaçôes brasileira, europeia e pelo Mercosul, além do estabelecido pelo Food and Drug Administration (FDA) (FDA, 2011) como ponto crítico de controle do pescado quando de sua chegada no porto.

O método oficial de análise de histamina no Brasil (Brasil, 1997a) é o mesmo utilizado pela União Europeia (Jornal Oficial das Comunidades Europeias, 2005), que preconiza que as análises sejam feitas por cromatografia líquida de alta eficiência (CLAE). O uso de CLAE é muito comum, porém apresenta um alto custo e maior tempo de análise (Avelar et al., 2005).

Existem muitas publicaçóes que relatam outras metodologias de análise de aminas bioativas em alimentos. No Brasil, a histamina vem sendo analisada por fluorimetria e cromatografia em camada delgada (CCD) principalmente. O método por fluorimetria envolve reação com agente derivatizante oftalaldeído, com etapas prévias de purificação do extrato em coluna de troca iônica (Horwitz, 2002). Isso resulta numa análise demorada e com produtos de derivatização pouco estáveis. Utilizando-se da CCD, a análise se torna mais crítica, pois a quantificação da histamina não é precisa, baseando-se na comparaçáo visual das manchas presentes na placa após eluição com padrôes nas concentraçóes críticas (Ромво et al., 2010).

De acordo com Avelar et al. (2005), o uso da cromatografia gasosa (CG) para análise de aminas bioativas em amostras biológicas está crescendo gradualmente. Entretanto, segundo KATAOKA (1996), a CG para aminas livres geralmente apresenta problemas relacionados à baixa massa molar, alta solubilidade em água e baixa volatilidade desses compostos

Também há disponível no mercado kits para detecção e quantificação de histamina em diferentes produtos alimentícios, como peixe fresco, salsichas, queijos e leite. Esses kits são testes ELISA, contendo todo o material necessário para a execução do método de quantificação, e não apresentam reaçóes cruzadas com outras aminas. São comercializados por empresas variadas e possuem como vantagem a rapidez da obtenção de resultados, em cerca de 60 minutos (SISBIO, 2015).

Vários índices químicos de qualidade são propostos para a avaliação da qualidade de pescado. A legislaçáo brasileira considera deteriorado e, portanto, impróprio para o consumo, o pescado com teor de bases voláteis superior ou igual a $30 \mathrm{mg}$ $\mathrm{N} / 100 \mathrm{~g}, \mathrm{pH}$ da carne externa superior ou igual a 6,8, da carne interna superior ou igual a 6,5 e reação positiva de gás sulfídrico (Brasıl, 1997b). Estudos, entretanto, têm indicado que, apesar de rápidos, simples e de baixo custo, esses parâmetros não são bons índices de qualidade de peixes, pois não são capazes de identificar estágios iniciais de deterioração, indicando apenas que o produto encontra-se em fases avançadas do processo (BоттA, 1995).

O teor de histamina é um método proposto como critério de qualidade de pescado, uma vez que baixos níveis são detectados em peixe recém-capturado, aumentando com a sua deterioração (Fernandez-SAlgueiro; Mackie, 1987). O conhecimento dos teores de histamina em pescado é útil na avaliação do seu potencial em causar intoxicação histamínica (TAYlor, 1986). Nizimani et al. (2008) comentaram que a histamina é considerada o mais importante indicador de frescor do pescado.

Tabela 1. Estudos relativos à presença da histamina em peixes das famílias susceptíveis.

\begin{tabular}{|c|c|c|c|c|c|}
\hline $\begin{array}{l}\text { Total de amostras } \\
\text { analisadas }\end{array}$ & Espécies & Período & Localidade & Teor de histamina & Fonte \\
\hline 864 & Família Scombridae & Jan/2007 a Dez/2009 & Costa Brasileira & $\begin{array}{l}\text { De acordo com } \\
\text { padrão estabelecido. }\end{array}$ & EVANGELISTA (2010) \\
\hline 180 & Atum fresco & Dez/2007 a Dez/2008 & $\begin{array}{l}\text { Rio Grande do } \\
\text { Norte }\end{array}$ & $\begin{array}{l}\text { De acordo com } \\
\text { padrão estabelecido. }\end{array}$ & OLIVEIRA (2009) \\
\hline 284 & $\begin{array}{l}\text { Sardinhas-verdadeira } \\
\text { e boca-torta }\end{array}$ & Mar/2009 a Jul/2009 & Cabo Frio (RJ) & $\begin{array}{l}\text { Todas abaixo do } \\
\text { padrão }\end{array}$ & SILVA (2010) \\
\hline 414 & Atum & $\mathrm{Abr} / 2001$ a Mar/2008 & Costa Brasileira & De acordo com UE. & SiLva et al. (2010) \\
\hline 102 & Albacora branca & 1994 a 1996 & $\begin{array}{l}\text { Oceano Pacífico } \\
\text { (EUA) }\end{array}$ & De acordo com FDA & GLóRIA et al. (1999) \\
\hline 33 & Cavala salgada & Jan a Mar/2003 & Ilha Formosa & Valores elevados & Tsal et al. (2005) \\
\hline
\end{tabular}




\section{ESCOMBROTOXICOSE}

A intoxicação histamínica recebe o nome de escombrotoxicose, sendo que os sinais e sintomas ocorrem de vários minutos a algumas horas após a ingestão da amina. A doença geralmente tem curta duração, de algumas horas, mas pode se estender a alguns dias. Para exercer todo seu potencial tóxico, a histamina deve atingir os tecidos periféricos e os tecidos extraintestinais (TAYLOR, 1986). Ela causa dilatação dos vasos sanguíneos periféricos, além de promover contração dos músculos do epitélio intestinal (Lehane; Olley, 2000).

Autores relatam que a atividade tóxica histamínica é potencializada pela presença de outras aminas biogênicas, como a tiramina, a cadaverina e a putrescina, que são produzidas concomitantemente à histamina, com a descarboxilação dos respectivos aminoácidos encontrados na forma livre, ou seja, tirosina, lisina e arginina (TAYLOR, 1986). Além disso, medicamentos podem ter efeito de inibição das enzimas diamino oxidase (DAO) e monoamina oxidase (MAO), substâncias que fazem a degradação das aminas através da desaminação oxidativa, ajudando a potencializar sua açấo (SATTLER; LORENZ, 1990). Essas substâncias potencializadoras fazem com que a dose de histamina necessária para causar uma intoxicação seja bem menor do que a prevista (STRATTON; TAYLOR, 1991).

Sintomas típicos da intoxicação são constituídos de enrubescimento da face e do pescoço, acompanhado de uma sensação de calor intenso, desconforto geral e diarreia. Brotoejas subsequentes na face e no pescoço são comuns. O enrubescimento é seguido por uma dor de cabeça intensa e palpitante, evoluindo para uma dor contínua e entorpecente. Outros sinais incluem vertigem, prurido, desmaios, queimação na boca e na garganta e incapacidade de deglutir (JAY, 2005).

A intoxicação por histamina é frequentemente confundida com alergias alimentares e os anti-histamínicos são eficazes no tratamento de ambas as doenças. No entanto, a intoxicação por histamina pode ser facilmente diferenciada da alergia por causa alimentar pela falta de um histórico anterior de reaçóes alérgicas, e por ocorrer em mais de uma pessoa ao mesmo tempo. Nas alergias alimentares, é raro que mais de uma pessoa em um grupo tenha sintomas causados por um alimento específico (TAYLOR, 1986).

O período de incubação é, em geral, de 30 minutos após a ingestão do produto contaminado, podendo variar até 2 horas. O diagnóstico presuntivo de intoxicação por histamina pode ser feito se os sinais e sintomas forem típicos e se o paciente tiver ingerido algum tipo de peixe que foi anteriormente apontado nos casos de intoxicação por histamina. A confirmação pode ser feita pela detecção de altos níveis de histamina nos alimentos (São Paulo, 2003).

Em casos mais graves o tratamento indicado é uma medicação anti-histamínica (SÃo Paulo, 2003). Os antagonistas do receptor $\mathrm{H} 1$ são os mais recomendados tanto para tratamento quanto para prevenção, e os pacientes geralmente respondem bem (Russel; Maretíc, 1986).

A distribuição geográfica da intoxicaçấo histamínica é mundial. De ocorrência ocasional e não raro, sob a forma de surtos, encontramos mais frequentemente em países onde é elevado o consumo das espécies de pescado envolvidas com altos teores de histamina (Veciana-Nogués et al., 1997). Mesmo sendo uma forma comum de intoxicação, o numero de casos é baixo. Muitos dos casos causam sintomas brandos ou seus sintomas são confundidos com o da infecção por Salmonella ou alergia alimentar (Russel; MARETíc, 1986). A Tabela 2 resume os surtos de intoxicação histamínica, em termos mundiais.

Desde 1970, os países que têm maior incidência de casos são Japão, Estados Unidos e Reino Unido (FDA, 2011). Há relatos de surtos em diversos outros países, como França, Dinamarca e Canadá. Os peixes das famílias Scombridae (atum, bonito, cavala), Scomberesocidae (tiravira), Pomatomidae (pomátomo), Coryphaenidae (dourado), Carangidae (olho-de-boi), Clupeidae (arenque, sardinha) e Engraulidae (anchova) foram os mais implicados nesses casos (TAYLOR, 1986).

A Ásia é o continente que tem mais casos descritos. No continente, a intoxicação por histamina foi a maior causa de doenças durante os anos 1950 e até hoje é a maior causa de intoxicaçôes (TAYLOR, 1986; Cinquina et al., 2004).

Segundo o FDA (2011), de 1960 a 1980 foram descritos 42 incidentes no Japão, envolvendo 4.122 indivíduos intoxicados. No ano de 1970, 40 crianças foram intoxicadas ao consumirem atum enlatado importado por um programa de merenda escolar. Especificamente, TAYLOR (1986) relatou que o maior surto no mundo ocorreu no Japão em 1973, envolvendo 2.656 casos, causados pelo consumo de carapau (família Scombridae) ressecado.

Tabela 2. Surtos de intoxicação histamínica após consumo de peixes.

\begin{tabular}{lccc} 
País & Período & $\begin{array}{c}\text { Número } \\
\text { de surtos }\end{array}$ & $\begin{array}{c}\text { Número } \\
\text { de casos }\end{array}$ \\
\hline Canadá & $1975-1981$ & $6^{*}$ & - \\
\hline Dinamarca & $1976-1982$ & 33 & - \\
& $1993-1998$ & 13 & - \\
\hline Finlândia & $1993-1998$ & 9 & $>722$ \\
\hline \multirow{2}{*}{ França } & $1980-1983$ & $10^{*}$ & $>500$ \\
& $1993-1997$ & 38 & - \\
\hline \multirow{2}{*}{ Japão } & $1950-1954$ & 14 & 1215 \\
& $1970-1980$ & $42^{*}$ & 4122 \\
\hline Suécia & $1993-1998$ & 4 & 12 \\
\hline \multirow{2}{*}{ Reino Unido } & $1976-1982$ & 136 & 439 \\
& $1987-1996$ & 105 & 405 \\
\hline \multirow{2}{*}{ Estados Unidos } & $1968-1981$ & $11 *$ & 888 \\
& $1973-1987$ & 202 & 1216 \\
& $1988-1998$ & 32 & 155 \\
\hline
\end{tabular}

*Surtos envolvendo outros alimentos, como carnes e queijos; - informação não disponível.

Fonte: SILVA, 2008. 
No Reino Unido, López-SABater et al. (1996) referiram-se à intoxicação histamínica como a segunda mais frequente causa para doença de origem alimentar decorrente do consumo de frutos do mar.

Entre os anos de 1976 a 1990, foram 441 suspeitas dentro de 962 casos de intoxicação no Reino Unido, sendo que em 1976 ocorreram mais de 100 surtos na Inglaterra, País de Gales e Escócia (Scoging, 1991). Entre 1980 e 1989 foram relatados 35 casos associados com peixe processado e mariscos (SockeTt, 1991).

Nos EUA existe uma grande dificuldade de determinar a quantidade de casos devido a informaçóes incompletas (LAnge et al., 2002). Em 1973, o Center for Disease Control norte-americano apresentou mais de 200 casos de intoxicação em suas estatísticas decorrentes de atum fresco, defumado ou em conserva (Merson et al., 1974).

No período de janeiro de 2005 a dezembro de 2007 ocorreram 21 surtos em Israel implicando peixes da família Scombridae (LAvon et al., 2008). Outro surto aconteceu na cidade de Kaohsiung, no sudoeste da Ilha Formosa no ano de 2007, acometendo 347 crianças em uma escola, sendo os peixes da família Istiophoridae (CHEN et al., 2010). Há relatos de outros surtos em diferentes países.

Não foram encontrados dados oficiais sobre ocorrências de intoxicação por histamina no Brasil. Vários casos de intoxicação histamínica não são registrados, uma vez que os sintomas podem ser relativamente leves, ter curta duração e as pessoas acometidas não procurarem apoio médico. Além disso, muitos médicos não têm conhecimento da intoxicação, desconsiderando-a como possível diagnóstico. Mesmo quando o diagnóstico é feito, muitos países não mantêm um registro oficial dos surtos. Sendo assim, não se conhece a incidência real da intoxicação histamínica (GLórIA, 2005).

Porém, podem ser encontrados na literatura alguns poucos casos relatando surtos de intoxicação por escombrídeos. EvangELISTA (2010) relatou que, durante a realização de seu estudo de detecção de histamina em escombrídeos, houve três surtos na região Nordeste do Brasil, comunicados à Vigilância Sanitária de Natal, Rio Grande do Norte, envolvendo atuns e acometendo um total de 25 pessoas.

Por meio da vigilância epidemiológica, se a intoxicação histamínica fosse uma doença de notificação compulsória, haveria registro de surtos. A notificação compulsória tem sido a principal fonte da vigilância epidemiológica, a partir da qual, na maioria das vezes, se desencadeia o processo informação-decisão-ação.
A listagem das doenças de notificação nacional é estabelecida pelo Ministério da Saúde entre as consideradas de maior relevância sanitária para o país (BRASIL, 2009).

Os dados coletados sobre as doenças de notificação compulsória são incluídos no Sistema Nacional de Agravos Notificáveis (SINAN). Estados e municípios podem adicionar à lista outras patologias de interesse regional ou local, justificada a sua necessidade e definidos os mecanismos operacionais correspondentes (Brasil, 2009). A escombrotoxicose deveria estar nessa lista, visto que uma grande parcela da população é acometida por essa intoxicação.

A intoxicação histamínica em pescado pode ocorrer quando a histamina atinge $500 \mathrm{mg} / \mathrm{kg}$ (RAwles et al., 1996). Dessa forma, limites ou níveis máximos aceitáveis têm sido estabelecidos em alguns países para histamina em pescado. Os níveis máximos adotados por cada país encontram-se resumidos na Tabela 3 .

Recentemente, a União Europeia estabeleceu barreiras à exportação de pescado de países que não efetuavam a análise dos teores de histamina muscular nesses alimentos, principalmente atuns e afins (Silva, 2008). Com isso, em 2006, a importação de pescado do Brasil foi impedida pela União Europeia após constatar em expedição ao país que existiam falhas graves no manuseio dos produtos da pesca, proporcionando uma deterioração mais rápida e favorecendo elevados níveis de histamina em espécies que têm alto teor de histidina livre (European Commission, 2006).

Considerando o levantamento realizado, torna-se clara a necessidade da aplicação das Boas Práticas de Manipulação alinhadas a outras ferramentas de controle de qualidade, como rastreamento, em todas as etapas do processamento do pescado.

\section{RASTREAMENTO DE PESCADO}

Um sistema de rastreamento do pescado é útil para os produtores por ser uma ferramenta que auxilia no controle de qualidade, visto que é possível rastrear a história do pescado, da coleta ou produção em tanque até o consumidor final (SuCASAs, 2011).

O pescado movimenta-se ao longo da cadeia de produção em lotes, os quais representam produtos da mesma espécie, do mesmo tratamento, e provenientes da mesma zona de captura e da mesma embarcação, ou da mesma unidade de produção (aquicultura) (Moura, 2009).

Tabela 3. Limites máximos estabelecidos em diferentes países para histamina em pescado.

\begin{tabular}{|c|c|c|}
\hline Localidade & Limites máximos estabelecidos & Fonte \\
\hline \multirow{2}{*}{ Estados Unidos } & $5 \mathrm{mg}$ histamina/100g amostra - produto no porto & \multirow{2}{*}{$\operatorname{FDA}(2011)$} \\
\hline & $10 \mathrm{mg}$ histamina/100g amostra - produto em conserva & \\
\hline \multirow{2}{*}{ União Europeia } & 9 amostras; nenhuma deve apresentar valor maior do que $200 \mathrm{mg} / \mathrm{kg}$ & JORNAL OFICIAL DAS COMUNIDADES \\
\hline & e apenas 2 entre 100 mg/kg e 200 mg/kg - famílias susceptíveis & EUROPEIAS(2005) \\
\hline Mercosul & 10 mg histamina/100g amostra - famílias susceptíveis & $\mathrm{ABIA}(1997)$ \\
\hline
\end{tabular}


A captura é o primeiro e, talvez, o mais importante, ponto na cadeia produtiva do pescado. Utilizando-se de um sistema de rastreamento, torna-se possível conhecer e verificar a origem do produto (LiU, 2006).

Segundo Almeida (2006), em Portugal, na hora do desembarque os lotes de pescado são separados quanto à espécie e acondicionados em caixas plásticas, e a essas são atribuídas um número de identificação, no qual constam nome do barco, área e dia de captura, número e peso do produto alojado nas caixas plásticas, entre outros. Quando as informaçôes são provenientes de diferentes embarcações faz-se necessária a utilização de um banco de dados para tornar o sistema de informaçóes válido.

$\mathrm{Na}$ comercialização de cada lote do pescado fresco, esta deve ser feita através de seu número de identificação, que remete a todas as informaçôes coletadas até o momento (Almeida, 2006).

Em relação à aquicultura, os produtos resultantes dessa atividade são sujeitos a um extremo controle, do qual resulta todo um conjunto de identificaçóes e registos efetuados ao longo do processo de cultivo. Os registros são efetuados com base no lote, o qual corresponderá ao pescado da mesma espécie e na mesma fase de produção (ovos, alevinos, juvenis e reprodutores), confinados ao mesmo tanque e de tamanho homogêneo. Os registos assentam num conjunto de informaçóes desde a quantidade e tipo de alimento fornecido, taxas de mortalidade e respectivas causas, dimensóes do pescado, medidas profiláticas (vacinas), medicação administrada, temperatura da água, entre outros, traduzindo-se numa produção programável e rastreável, onde cada peixe tem um "bilhete de identidade", sabendo-se todo seu histórico (Moura, 2009).

Quando destinados à indústria de processamento, tanto os produtos da pesca como os de aquicultura deverão receber em sua chegada um novo número de identificaçáo (identificação de entrada), o qual é registado e devidamente relacionado com o número de lote inicial, correspondente ao anteriormente atribuído (Moura, 2009).

Segundo Moura (2009), após o processamento do pescado, é atribuído um novo número de identificação, correspondente ao lote de produção de um dia, o qual irá figurar na embalagem dos produtos e ao qual a indústria irá associar as suas vendas.

Após expedição dos produtos, no caso de se identificar algum risco à saúde pública associado a eles, a indústria, através dos registros efetuados, deve ser capaz de identificar o fornecedor dos respectivos produtos, o qual, atuando da mesma forma, deverá identificar o barco de pesca do qual foi capturado o pescado ou, no caso de se tratar de um produto de aquicultura, o seu tanque proveniente (Moura, 2009).

A transmissão das informaçóes para fins de rastreamento pode ser feita através de registros de papel, ou de forma eletrônica com a transferência de arquivos através de CD, endereços eletrônicos ou websites na Internet, ou código de barras e, mais recentemente, RFID3, transmissão de dados ou identidades
(ID) via frequência de rádio por meio de pequenos chips presentes na embalagem (CARvalHo, 2006).

De acordo com Carvalho (2006), um dos pontos de partida para a implementação do rastreamento é o conhecimento da cadeia de produção, suprimentos, transformação e logística do produto em questão, que durante a sua vida útil irá percorrer várias etapas. A cada estágio de sua transformação, o produto deverá receber uma nova identificação para ser rastreável (identificação e registro). No processo de distribuição, entretanto, essa identificação passo a passo não é mais necessária, pois o produto é rastreado através de sua identificação original.

Segundo Firetti; Sales (2003), no caso da piscicultura, é possível instalar um processo de rastreamento 100\% seguro, pelo menos em relação à origem dos alevinos, através do DNA, que permite acompanhar o peixe desde seus primórdios de vida até seu consumo. Com esse sistema é possível chegar ao limite, caso seja necessário, de pegar um pedaço de filé no prato de um restaurante em qualquer lugar do mundo e saber se o peixe, do qual proveio, nasceu, por exemplo, no Brasil e, mais especificamente, em qual laboratório de reprodução foi gerado.

Conforme Kubitza (2007), um dos requisitos para a consolidação do Brasil como um dos maiores produtores de tilápia do mundo é a execução de açóes que garantem o rastreamento e segurança do produto.

\section{PANORAMA MUNDIAL DO RASTREAMENTO DE PESCADO}

No tocante ao rastreamento em produtos pesqueiros, a Comunidade Europeia se destacou por ser a primeira a adotar esses princípios, em 2003, através do documento Fish Labelling Regulations (Reino Unido, 2013).

O Comitê Europeu de Normatização realizou um programa, de 2000 a 2002, intitulado Rastreamento de Produtos do Pescado ou TraceFish. O TraceFish foi fundado sob um programa temático "Qualidade de vida e manejo de recursos vivos" (Quality of life and management of living resources). Originalmente, 24 companhias e/ou institutos de pesquisa eram os parceiros desse consórcio, mas como o projeto e o processo de padronização cresceram, o número de participantes ao final era bem maior do que 100 . O projeto reuniu companhias e institutos de pesquisa para estabelecer visóes comuns com respeito a quais dados deveriam seguir um produto de pescado, através da cadeia, desde a captura ou fazenda até o consumidor (CEN, 2003).

De acordo com os padróes do Tracefish para pescado capturado, a chave para produtos de pescado rastreado é a rotulagem de cada unidade de pescado comercializada desde o produto in natura até o produto final com um único número de identificação (ID) (CEN, 2003). 
Os regulamentos dos EUA não designam o rastreamento, porém eles contêm os conceitos fundamentais do sistema. A legislação sobre segurança nas fazendas e em investimentos rurais (U.S. Farm Security and Rural Investment Act of 2002) requer que o país de origem identifique toda carne bovina, de cordeiro, suínos, peixes e artigos perecíveis. Diretrizes voluntárias foram estabelecidas em outubro de 2002, e passaram a ser obrigatórias a partir do dia 30 de setembro de 2006 para todos os artigos, excluindo os peixes e moluscos, que foram implementados em 4 de abril de 2005 (Oetterer, 2008).

A execução obrigatória do Country of Origin Labeling (COOL) requer que todos os abastecedores etiquetem claramente a origem de todo o pescado. A análise de custo benefício do COOL feita pelo Serviço de Marketing Agrícola estima que o custo do primeiro ano foi de 3,9 bilhóes de dólares para criar e manter o sistema de informação COOL (Oetterer, 2008). Além do COOL, há a lei de responsabilidade que trata do bioterrorismo (U.S. Bio-terrorism and Response Act of 2002), efetivada a partir de 12 de junho de 2002. Essa lei requer o registro de todos os negócios e unidades ou instalaçóes de alimentos, domésticas e estrangeiras, que abastecem os EUA, além de designar registros para identificar os provedores e receptores de todos os produtos alimentícios, que são informações relacionadas ao rastreamento (Thompson et al., 2005).

Um sistema de rastreamento também foi desenvolvido para o pescado fresco na Dinamarca. Essa pesquisa focalizou todos os aspectos da cadeia do pescado fresco e usou código de barras e códigos seriados nos contêineres de remessa para identificar cada unidade e localizar cada entrega. A pesquisa teve êxito em mostrar que o rastreamento pode ser alcançado e reconheceu o fato de que o custo do sistema para embarcaçóes e empresas pequenas precisa ser avaliado e que devem ser desenvolvidas interfaces dos usuários mais próximos para promover a eficiência. Na Escócia, nas Ilhas de Shetland, promove-se o rastreamento na cadeia do pescado instalando sistemas em dez embarcaçóes como parte do Projeto Pescado da Escócia. Existem tentativas de implantação de sistemas de rastreamento no Japão (Thompson et al., 2005). Em Portugal, desde 2003, está estabelecido o regime de rastreamento e controle das exigências de informaçáo ao consumidor que está sujeito à venda de produtos de pesca e aquicultura (Moura, 2009).

\section{PRINCIPAIS DESAFIOS DO BRASIL PARA A IMPLANTAÇÃO DO RASTREAMENTO EM PESCADO}

A atividade pesqueira no Brasil não teve reconhecimento mais estratégico nas políticas públicas do país. A definição da competência do setor pesqueiro para um único órgão federal e a consequente definição de políticas pesqueiras só ocorreram em 2003, com a criação da Secretaria Especial de Aquicultura e Pesca da Presidência da República (SEAP/PR) (Brasil, 2003). Em 26 de junho de 2009, através da Lei $n^{\circ} 11.958$ (transformação), que altera as Leis $\mathrm{n}^{\text {os }} 7.853 / 1989$ e $10.683 / 2003$ SEAP/PR, foi criado o Ministério da Pesca e Aquicultura. Essa iniciativa veio ao encontro da necessidade do poder público atuar de forma gestora nas atividades de pesca e beneficiamento do pescado (Brasil, 2009)

Atualmente, a regulação do setor está dividida entre os Ministérios da Pesca e Aquicultura (MPA), o MAPA e a Agência Nacional de Vigilância Sanitária (ANVISA). O MPA é o órgão responsável pelo controle de doenças de animais aquáticos no território nacional, bem como pelo controle da presença de resíduos químicos e contaminantes naturais nos recursos pesqueiros (animais vivos, no ambiente natural sob cultivo) (Brasıl, 2009); o MAPA é responsável pela inspeção de pescado destinado ao consumo humano, com os parâmetros de segurança e inocuidade definidos pelo Serviço de Inspeção Federal (SIF-MAPA) (BrAsıl, 1997b); e a ANVISA é responsável pelo controle e pela vigilância sanitária dos locais de venda no varejo, como supermercados, restaurantes e feiras livres (BrasiL, 1999).

Outro ponto a ser considerado é a consequente desvalorização dos produtos da pesca, levando à descapitalização da base da cadeia produtiva, com carência de instalaçóes adequadas para o processamento e armazenamento do pescado e a grande participação de segmentos sociais marginalizados na atividade pesqueira. Como consequência, a pesca no Brasil pode ser considerada artesanal e de baixa produtividade (Biondi et al., 2007).

Através do perfil apresentado, pode-se inferir que o estabelecimento de um sistema de rastreamento em pescado no Brasil ainda exigirá um processo de longo prazo, mesmo considerando-se iniciativas como a do MPA para a criação da Rede Nacional de Laboratórios do Ministério da Pesca e Aquicultura (RENAQUA) (BRAsil, 2012). Para uma organização adotar o rastreamento como um requisito de gestão, há a necessidade de montar, documentar e manter uma matriz de rastreamento que faça parte de um amplo sistema de gestão da qualidade, uma política consensual e acordada em todo o âmbito da empresa (Giordano, 2009). Esse modelo seria adaptável ao sistema de aquicultura, entretanto, de difícil implantação em cenários que vivenciam a pesca artesanal.

Segundo Biondi et al. (2007), deve haver um consenso em seguir a mesma trajetória do projeto europeu TraceFish, que estabeleceu as diretrizes para toda a cadeia produtiva, ou seja, desde que o pescado é capturado até a mesa do consumidor. Entretanto, deve-se refletir sobre as peculiaridades de cada situaçáo. Inclusive a questão do grau de escolaridade dos pescadores brasileiros deve ser levada em conta. 
OetTerer; Galváo (2005) relataram que um sistema de rastreamento para o pescado brasileiro, além de ser uma ferramenta de extrema necessidade, é uma inovação tecnológica, visto que poucos países no mundo avançaram nessa direção. $\mathrm{O}$ rastreamento da cadeia produtiva do pescado nacional pretende equiparar o Brasil a esse contingente, fato que caracteriza o impacto tecnológico no setor.

O desenvolvimento de um sistema de rastreamento informatizado para o pescado brasileiro terá, dentro de poucos anos, elevada importância comercial por constituir um processo com agilidade e segurança e que agregará valor à cadeia produtiva do pescado. É preciso acompanhar essa tendência, principalmente devido à importância desse mercado para a sociedade brasileira (Oetterer; Galvão, 2005).

Para enfrentar as barreiras técnicas que estão sendo erguidas em nome da inocuidade do alimento, principalmente pela Europa, o rastreamento representa um passaporte para inserção e consolidação do Brasil no mercado mundial (Galvấo, 2011).

Atualmente, há a proposta da instalação de um software desenvolvido para promover o rastreamento em pescado oriundo das atividades de pesca e aquicultura. O Sistema Brasileiro de Rastreabilidade em Pescado, conhecido como SiBRaP, conta com o lacre identificador de lote e rastreamento em peixes in natura e a etiqueta identificadora de lote e rastreamento para pescado in natura e/ou industrializados. As novas tecnologias aplicadas a esse sistema, funcionando no âmbito da Internet, proporcionam ao consumidor informaçôes importantes, como a localizaçáo do empreendimento com dados de GPS, a procedência das matrizes e métodos de abate, os sistemas de cultivos, raçóes e medicamentos utilizados, e outras (AQuABio, 2012).

Cabe notar que o sistema de rastreamento, isoladamente, é insuficiente para garantir a segurança do alimento. A sua implantação antecede o amadurecimento da implementação das boas práticas, seja as Boas Práticas Agrícolas ou as Boas Práticas de Manipulaçáo e do sistema de Análise de Perigos e Pontos Críticos de Controle (APPCC).

\section{CONCLUSÃO}

A viabilizaçáo do rastreamento para controle de histaminas em pescado requer da organizaçáo investimento em capacitaçấo do pessoal envolvido, investimento no tocante à aquisiçâo do material necessário à análise e diminuiçáo da rotatividade da mão de obra.

No Brasil, há carência de dados epidemiológicos, causada principalmente pela má qualidade e deficiência de dados estatísticos, e o monitoramento de doenças é realizado de forma inferior. As autoridades brasileiras deveriam ter melhor estudo sobre a inocuidade de alimentos, incluindo a prevenção da formação da histamina e consequente intoxicaçấo. Também é papel da indústria pesqueira possuir alertas quanto a temperaturas de formação da histamina, o que ajudaria na diminuição.

A instalação de um sistema de rastreamento é um forte requisito para as indústrias de pescado se manterem no mercado internacional, e as ferramentas disponíveis para a sua implementação permitem que essa tarefa seja realizada com um alto grau de sucesso, trazendo benefícios para a empresa através do controle de processos, custos, segurança e imagem positiva perante o consumidor.

Uma vez realizado o sistema na produçáo pesqueira, os níveis de agravos à saúde relacionados à histamina irăo diminuir, visto que haverá uma maior segurança frente a todas as etapas produtivas do pescado. Além disso, haverá uma maior facilidade de recolhimento do produto e investigação detalhada, em caso de alergias à substância química, identificando corretamente em qual etapa esta provavelmente foi produzida.

Para garantir a inocuidade do pescado, torna-se imprescindível a capacitação da mão de obra envolvida em todos os pontos da cadeia, para que saiba monitorar e corrigir quando necessário as condiçóes a que estiver submetido cada lote de pescado. Evidentemente que os organismos de fiscalizaçâo sanitária deverão estar cada vez mais preparados para seguir de perto todos os procedimentos a cargo das empresas beneficiadoras, das transportadoras e dos atacadistas/varejistas para garantir a qualidade/inocuidade do pescado in natura e seus derivados industrializados.

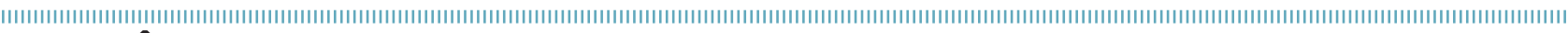
REFERÊNCIAS

ABIA (ASSOCIAÇÃO BRASILEIRA DAS INDUSTRIAS DE ALIMENTAÇÃO). Identidad y calidad de pescado fresco. Mercosur/ GMC, Resolução 40/94. In: Compêndio das Resoluções do Mercosul. São Paulo, 1997. p. 76-78.

ALMEIDA, J. Traceability and quality in a fresh fish export chain - an Icelandic and Capverdian study. 2006. 80 f. Projeto Final (Fisheries Training Programme) - The United Nations University, Iceland, 2006.
ARNOLD, S.H.; BROWN, W.D. Histamine (?) toxicity from fish products. Advances in Food Research, v.24, p.113-154, 1978.

AVELAR, E.C.; FRANÇA, A.S.; FERRAZ, V.P. Desenvolvimento e otimização de metodologia de cromatografia gasosa para identificação e quantificação de aminas bioativas em alimentos. In: CONGRESSO BRASILEIRO DE ENGENHARIA QUÍMICA EM INICIAÇÃO CIENTÍFICA. Anais. Campinas: ABEQ; 2005. 6p. 
AQUABIO. SiBRaP - Sistema Brasileiro de Rastreabilidade em Pescado [Internet]. Promove a apresentação do SiBRaP. Disponível em: http://www.aquabionet.com.br/2011/6/1/sibrap-sistemabrasileiro-de-rastreabilidade-em-pescado. Acesso em: 28 set. 2012.

BALDINI, V.L.S. Aminas biogênicas e a deterioração do pescado. Boletim do Instituto de Tecnologia de Alimentos, v.19, p.389402, 1982.

BOTTA, J.R. Evaluation of seafood freshness quality. Chapter 1, Chemical methods of evaluating freshness quality. New York: $\mathrm{VCH} ; 1$ 1995. p.9-33.

BIONDI, G.F.; CARVALHO, E.D.; DAVID, G.S. Condições de pesca nos reservatórios do Tietê: a situação na bacia do médio Tietê, Sorocaba, SP. Revista Higiene Alimentar, v.21, n.151, p.126-127, 2007.

BRASIL. Ministério da Agricultura e do Abastecimento. Portaria no 185, de 13 de maio de 1997. Institui o Regulamento Técnico de Identidade e Qualidade do Peixe Fresco (Inteiro ou Eviscerado). Diário Oficial da União, Brasília, 19 de maio de 1997a.

BRASIL. Ministério da Agricultura, Pecuária e Abastecimento. Secretaria de Defesa Agropecuária. Departamento de Inspeção de Produtos de Origem Animal. Decreto n० 30.691, de 29 de março de 1952, alterado pelos decretos no 1.255 de 25 de junho de 1962 , n० 1.236 de 02 de setembro de $1994, n^{\circ} 1.812$ de O8 de fevereiro de 1996 e n 2.244 de 04 de junho de 1997. Aprova o Regulamento da Inspeção Industrial e Sanitário de Produtos de Origem Animal. Diário Oficial da União, Brasília, 05 de junho de 1997b. Seção 1, p. 241.

BRASIL. Agência Nacional de Vigilância Sanitária. Decreto nº 3.029, de 16 de abril de 1999. Aprova o Regulamento da Agência Nacional de Vigilância Sanitária, e dá outras providências. Diário Oficial da União, Brasília, 19 de abril de 1999. Seção 1.

BRASIL. Lei no 10.683 , de 28 de maio de 2003. Dispõe sobre a organização da Presidência da República e dos Ministérios, e dá outras providências. Diário Oficial da União, Brasília, 29 de maio de 2003.

BRASIL. Ministério da Pesca e Aquicultura (MPA). Lei no 11.958, de 26 de junho de 2009 . Altera as Leis n० 7.853 , de 24 de outubro de 1989, e 10.683, de 28 de maio de 2003; dispõe sobre a transformação da Secretaria Especial de Aquicultura e Pesca da Presidência da República em Ministério da Pesca e Aquicultura; cria cargos em comissão do Grupo-Direção e Assessoramento Superiores - DAS e Gratificações de Representação da Presidência da República; e dá outras providências. Diário Oficial da União, Brasília, 29 de junho de 2009.

BRASIL. Ministério da Pesca e Aquicultura (MPA). Instrução Normativa $n^{\circ} 3$, de 13 de abril de 2012. Institui a Rede Nacional de Laboratórios do Ministério da Pesca e Aquicultura (RENAQUA). Diário Oficial da União, Brasília, 18 de abril de 2012.

CARMO, F.B.T.; MÁRSICO, E.T.; CLEMENTE, SCS; CARMO, R.P.; FREITAS, M.Q. Histamina em conservas de sardinha. Revista Ciência Animal Brasileira, v.1 1, n. 1, p.174-180, 2010.

CARVALHO, R.A.P.L.F. Implementação de sistemas de rastreabilidade na cadeia de produção de pescado. In: II SIMPÓSIO DE CONTROLE NO PESCADO. Anais. São Vicente: SIMCOPE, 2006. 6p.
CEN. COMITÉ EUROPÉEN DE NORMALISATION. Traceability of fishery products: specifications of the information to be recorded in captured fish distribution chains. Bélgica: CEN Workshop Agreement; 2003. $41 \mathrm{p}$.

CHEN, H.C.; HUANG, Y.R.; HSU, H.H.; LIN, C.S.; CHEN, W.C.; LIN, C.M.; TSAI, Y.H. Determination of histamine and biogenic amines in fish cubes (Tetrapturus angustirostris) implicated in a food-borne poisoning. Food Control, v.21, n.1, p.13-18, 2010.

CINQUINA, A.L.; LONGO, F.; CALI, A.; DE SANTIS, L.; BACCELLIERE, R.; COZZANI, R. Validation and comparison of analytical methods for the determination of histamine in tuna fish samples. Journal of Chromatography A, v.1032, n.1-2, p.79-85, 2004.

EUROPEAN COMISSION. DG n 8233/2006. Draft report of a mission carried out in Brazil from 12 to 22 June 2006 in order to access the public health controls and conditions of production of fishery products. Health \& Consumer protection directorate-general, 08 set. 2006, p.1-19. Disponível em: <http://ec.europa.eu/food/ fvo/act_getPDF.cfm?PDF_ID=5589>. Acesso em: O7 nov 2015.

EVANGELISTA, W.P. Prevalência de histamina em peixes escombrídeos e intoxicação histamínica no Brasil de 2007 a 2009. 2010. 70f. Dissertação (Mestrado em Ciência de Alimentos) - Faculdade de Farmácia, Universidade Federal de Minas Gerais, Belo Horizonte, 2010.

FERNANDEZ-SALGUERO, J.; MACKIE, I.M. technical note: preliminary survey of the content of histamine and other higher amines in some samples of Spanish canned fish. International Journal of Food Science \& Technology, v.22, n.4, p.409-412, 1987.

FDA. FOOD AND DRUG ADMINISTRATION. Fish and fishery products hazards and controls guidance. 4 ed. Washington: Office of Seafood; 2011 . Chap. 7. p.113-152.

FIRETTI, R.; SALES, D.E. AnualPec - Anuário da Pecuária Brasileira. 10 ed. São Paulo: FNP Consultoria e Comércio; 2003. Capítulo 11, Rastreabilidade com alta tecnologia na piscicultura, p.323-325.

GALVÃO, J.A. Rastreabilidade da cadeia produtiva do pescado: avaliação de parâmetros ambientais e sua influência na qualidade da matéria-prima destinada à indústria. 2011 . 202f. Tese (Doutorado em Química na Agricultura e no Ambiente) - Centro de Energia Nuclear na Agricultura, Universidade de São Paulo, Piracicaba, 2011.

GILBERT, R.J.; HOBBS, G.; MURRAY, C.K.; CRUICKSHANK, J.G.; YOUNG, S. Scombrotoxic fish poisoning: features of the first 50 incidents to be reported in Britain (1976-9). British Medical Journal, v.281, n.6233, p.71-72, 1980.

GIORDANO, J.C. Rastreabilidade em alimentos e rações: um dossiê da história de cada produto feito - e bem feito. Revista Higiene Alimentar, v.23, n.172/172, p. 200-2001, 2009.

GLÓRIA, M.B.A. Handbook of food science, technology and engineering. 6th ed. New York: CRC Press; 2005. 632p.

GLÓRIA, M.B.A.; DAESCHEL, M.A.; CRAVEN, C.; HILDERBRAND JR, K.S. Histamine and other biogenic amines in albacore tuna. Journal of Aquatic Food Products and Technology, v. 8, n. 4, p. 55-69, 1999. 
HORWITZ, W. Official Methods of Analysis. 17th ed. Arlington: Association of Official Analytical Chemists; 2002. 2.200p.

HUSS, H.H. Garantia da qualidade dos produtos da pesca. FAO Documento Técnico sobre as Pescas No. 334. Roma: FAO; 1997. 176p.

IENISTEA, C. Significance and detection of histamine. Londres: Academic Press; 1973. p.327-343.

JAY, J.M. Microbiologia de alimentos. 6 ed. São Paulo: Artmed; 2005. 706p.

JORNAL OFICIAL DAS COMUNIDADES EUROPEIAS. Regulamento (EC) $n^{\circ} 2073$, de 15 de novembro de 2005. Relativo à critérios microbiológicos aplicáveis aos gêneros alimentícios. Jornal Oficia das Comunidades Europeias, Luxemburgo, L 338/1-26, 2005.

KATAOKA, $\mathrm{H}$. Derivatization reactions for the determination of amines by gas chromatography and their applications in environmental analysis. Journal of Chromatography A, v.733, n. 1-2, p.19-34, 1996.

KIBUTZA, F. Tilápias na bola de cristal. Panorama da Aquicultura, v.17, n.99, p.14-21, 2007.

KIM, S.H.; BEN-GIGIREY, B.; BARROS-VELÁZQUEZ, J.; PRICE, R.J.; $\mathrm{AN}, \mathrm{H}$. Histamine and biogenic amine production by Morganella morganii isolated form temperature-abused albacore. Journal of Food Protection, v.63, n.2, p. 244-51, 2001.

LANGE, J.; THOMAS, K.; WITTMAN, C. Comparison of a capillary electrophoresis method with high-performance liquid chromatography for the determination of biogenic amines in various food samples. Journal of Chromatography B, v.779, n.2 p.229-239, 2002.

LAVON, O.; LURIE, Y.; BENTUR, Y. Scombroid fish poisoning in Israel, 2005-2007. Israel Medical Association Journal, v.10, n. 11, p.789-792, 2008.

LEHANE, L.; OLLEY, J. Histamine fish poisoning revisited: review. International Journal of Food Microbiology, v.58, n. 1 2, p. $1-37,2000$.

LIU, J. Investigation on traceability of fish products in Iceland: a traceability study for fish processing industry in China. 2006. 56f. Projeto Final (Fisheries Training Programme) - The United Nations University, Iceland, 2006.

LÓPEZ-SABATER, E.I.; RODRÍGUEZ-JEREZ, J.J.; HERNÁNDEZ HERRERO, M.; MORA-VENTURA, M.T. Incidence of histamine-forming bacteria and histamine content in Scombroid fish species from retail markets in the Barcelona area. International Journal of Food Microbiology, v. 28, n. 3, p. 411-418, 1996.

MACHADO, J.G.C.F.; NANTES, J.F.D. A visão institucional do processo de rastreabilidade da carne bovina. In: SBI-AGRO Anais. Santarém: APDTICA; 2004. p.11.

MERSON, M.H.; BAINE, W.B.; GANGAROSA, E.J.; SWANSON, R.C. Scombroid fish poisoning: outbreak traced to commercially canned tuna fish. The Journal of the American Medical Association, v.228, n.10, p.1268-1269, 1974
MOURA, A.P. Identificação e rastreabilidade de produtos de origem animal ao longo da cadeia alimentar. 2009. 39f. Dissertação (Mestrado integrado em Medicina Veterinária) - Instituto de Ciências Biomédicas Abel Salazar, Universidade do Porto, Porto, 2009.

NIZIMANI, A.G.; PALEOLOGOS, E.K.; SAVVAIDIS, I.N.; KONTOMINAS, M.G. Formation of biogenic amines and relation to microbial flora and sensory changes in smoked turkey breast fillets under various packaging conditions at 4 degrees C. Food Microbiology, v.25, n.3, p.509-517, 2008.

OETTERER, M. Rastreabilidade na pesca e aquicultura. In: III SIMPÓSIO DE CONTROLE NO PESCADO. Anais. São Vicente: SIMCOPE; 2008. p.4

OETTERER, M.; GALVÃO, J.A. Rastreabilidade da cadeia produtiva de pescado cultivado - Tilápia (Oreochromis niloticus). Brasília: Projeto MCT/FINEP; 2005. p.22.

OLIVEIRA, H.A.C.; SILVA, H.C.M.; SAMPAIO, A.H.; VIANNA, F.A.; SALTER-SAMPAIO, S. Determinação de histamina por cromatografia líquida de alta eficiência de fase reversa em atum e sardinha enlatados. Revista Ciência Agronômica, v.35, p. $179-188,2004$

OLIVEIRA, R.B.A. Qualidade de atuns tipo exportação capturados pelo espinhel pelágico no litoral de Pernambuco e Rio Grande do Norte, Brasil. 2009. 107 f. Dissertação (Mestrado em Ciência e Tecnologia de Alimentos)-Departamento de Ciências Domésticas, Universidade Federal Rural de Pernambuco, 2009.

POMBO, C.R.; MÁRSICO, E.T.; SCHULZ, D.F.; GODOY, R.L.O.; PACHECO, S. Desenvolvimento de novo método de análise de histamina, putrescina e cadaverina por CLAE utilizando derivação com 6-aminoquinolil-n-hidroxisuccinimidil carbamato (AQC). In: III SIMPÓSIO DE SEGURANÇA ALIMENTAR. Anais. Florianópolis: sbCTA-RS; 2010. p.4.

RAWLES, D.D.; FLICK, G.J.; MARTIN, R.E. Biogenic amines in fish and shellfish. Advances in Food and Nutrition Research, v.39, p.329-365, 1996

REINO UNIDO. The Fish Labelling Regulations [Internet]. No 1768. 2013. Disponível em: <http://www.legislation.gov.uk/ uksi/2013/1768/contents/made>. Acesso em: O7 nov 2015.

RODRIGUES, K.B. Histamina x Pescado: revisão bibliográfica. 2007. 24 f. Trabalho de Conclusão de Curso (Graduação em Medicina Veterinária) - Faculdade de Medicina Veterinária, Centro Universitário Vila Velha, Vila Velha, 2007.

RUSSEL, F.E.; MARETIC, Z. Scombroid poisoning: mini-review with case histories. Toxicon, v.24, n.10, p.967-973, 1986.

SÃO PAULO. Secretaria de Estado da Saúde de São Paulo. Manual das doenças transmitidas por alimentos: toxina escombroide. Informe NET-DTA. São Paulo: Centro de Vigilância Epidemiológica; 2003. p.4.

SATTLER, J.; LORENZ, W. Intestinal diamine oxidases and enteralinduced histaminosis: studies of three prognostic variables in an epidemiological model. Journal of Neural Transmission, Supplementum, v.32, p.291-314, 1990. 
SCOGING, A.C. Illness associated with seafood. Communicable Disease Report, v.1, n.11, p.117-122, 1991.

SILVA, S.C. Validade comercial de sardinhas inteiras e refrigeradas avaliada por análises físico-químicas, bacteriológicas e sensorial. 2010. 107 f. Dissertação (Mestrado em Higiene Veterinária e Processamento Tecnológico de Produtos de Origem Animal)Faculdade de Veterinária, Universidade Federal Fluminense, Niterói, 2010.

SILVA, T.M. Otimização e validação de método para determinação de histamina em pescado. 2008. 103f. Dissertação (Mestrado em Ciência de Alimentos) - Faculdade de Farmácia, Universidade Federal de Minas Gerais, Belo Horizonte, 2008.

SILVA, T.M.; SABAINI, P.S.; EVANGELISTA, W.P.; GLÓRIA, M.B.A. Occurrence of histamine in Brazilian fresh and canned tuna. Food Control, Estados Unidos: Elsevier, 2010.

SISBIO. Kit Histamina [Internet]. São Paulo;Venda de produtos relacionados a controle de qualidade e diagnósticos. Disponível em: <http://www.sisbio.pt/index.php/produtos-e-servicos/ kits/32-testes-para-alimentos/alergenios-e-intolerantes/111kit-histamina-ci015>. Acesso em: 07 nov 2015.

SOCKETT, P.N. Food poisoning outbreaks associated with manufactured foods in England and Wales. Communicable Disease Report, v.1, n.10, p.105-109, 1991.
STRATTON, J.E.; TAYLOR, S.L. Microbiology of Marine Food Products. New York: Van Nostrand Reinhold; 1991. Chap. 7, Scombroid poisoning. p.331-351.

SUCASAS, L.F.A. Avaliação do resíduo do processamento de pescado para o desenvolvimento de co-produtos visando o incremento da sustentabilidade da cadeia produtiva. 2011 . $164 \mathrm{f}$. Tese (Doutorado em Ciências) - Centro de Energia Nuclear na Agricultura, Universidade de São Paulo, Piracicaba, 2011.

TAYLOR, S.L. Histamine poisoning associated with fish, cheese and other foods. Geneva: World Health Organization; 1986. 47 p.

THOMPSON, M.; SYLVIA, G.; MORISSEY, M.T. Seafood traceability in the United States: current trends, system design, and potential applications. Comprehensive Reviews in Food Science and Food Safety, v.4, n.1, p.1-7, 2005.

TSAI, Y.H.; LIN, C.Y.; CHANG, S.C.; CHEN, H.C.; KUNG, H.F.; WEI, C.I.; HWANG, D.F. Occurrence of histamine and histamine-forming bacteria in salted mackerel in Taiwan. Food Microbiology, v.22, n.5, p.461-467, 2005.

VECIANA-NOGUÉS, M.T.; MARINÉ-FONT, A.; VIDAL-CAROU, M.C. Biogenic amines as hygienic quality indicators of tuna: relationships with microbial counts, ATP- related compounds, volatile amines, and organoleptic changes. Journal of Agricultural and Food Chemistry, v.45, n.6, p.2036-2041, 1997. 